\title{
Dictadura salazarista, descolonización y solidaridad holandesa. El caso del Angola Comité y el cIDAC*
}

\author{
Salazar Dictatorship, Decolonization, \\ and Dutch Solidarity. The Case of the \\ Angola Committee and CIDAC
}

\author{
Dirk Kruijt** \\ (D) https://orcid.org/0000-0002-9796-8127 \\ Department of Cultural Anthropology \\ Faculty of Social and Behavioural Sciences \\ Utrecht University, The Netherlands \\ d.kruijt@uu.nl
}

* Agradezco a José Manuel Ágreda Portero y a Eduardo Rey Tristán por sus comentarios y sugerencias leyendo las versiones anteriores de este artículo. Agradezco por su colaboración a Paul Staal (Angola Comité, Amsterdam), Kier Schuringa (International Institute of Social History, Amsterdam), José Dias, Luís Moita, Luísa Teotónio Perreira, Cecilia Fonseca, Cristina Cruz y Stephane Laurent (Centro de Intervenção para o Desenvolvimento Amílcar Cabral, Lisboa) y Natércia Coimbra (Centro de Documentação 25 de Abril, Coimbra) su ayuda en los archivos y los datos disponibles. También quiero hacer una mención especial a la colaboración del general Pedro de Pezarat Correia, presidente fundador de la Associação 25 de Abril, quien en abril de 1974 fue el representante del Movimiento das Forças Armadas en Angola, por su orientación sobre el proceso de descolonización.

** Professor Emeritus of Development Studies, Faculty of Social and Behavioural Sciences (FSw), Utrecht University, The Netherlands. Investigador Integrado Centro de Estudos Internacionais (CEI), Instituto Universitário de Lisboa (ISCTE-IUL), Portugal. Research Fellow Centre for Military Studies (CEMIS), Faculty of Military Science, Stellenbosch University, South Africa.

Cómo CITAR: Kruijt, D. (2020). Dictadura salazarista, descolonización y solidaridad holandesa. El caso del Angola Comité y el CIDAC. Secuencia (108), e1833. DoI: https://doi.org/10.18234/secuencia.v0i108.1833

\section{c) 9}

Esta obra está protegida bajo una Licencia Creative Commons Atribución-NoComercial 4.0 Internacional. 
Resumen: Este artículo analiza las actividades solidarias en Portugal y Holanda en relación con la descolonización e independencia del África Lusófona. En primer lugar, se plantearán las transformaciones sociopolíticas acaecidas en Holanda durante los años sesenta y el paso de la dictadura salazarista a una democracia en Portugal. A continuación, se pretenden explicar las actividades del Angola Comité de Amsterdam y su contribución a la creación del Centro de Intervenção para o Desenvolvimento Amílcar Cabral (CIDAC) en Lisboa. La investigación surgió con base en fuentes primarias: historia oral y documentación de archivo. Para este caso se han realizado diversas entrevistas a los principales actores y se han consultado el International Institute of Social History (IISH) en Amsterdam, el Centro de Documentação 25 de Abril (CD25A) asociado a la Universidade de Coimbra y el cIDAC en Lisboa.

Palabras clave: solidaridad; guerras coloniales; dictadura; Portugal y los Países Bajos.

Abstract: In this article I discuss the solidarity activities in Portugal and the Netherlands in the course of the process of decolonization and independence of Lusophone Africa. Firstly, I present the socio-political transformations in the Netherlands during the 1960s and the radical change in Portugal, from Salazar's dictatorship to democracy. Then I narrow the focus on the endeavors and performance of the Dutch Angola Komité in Amsterdam and its support to the Center of Intervention for Development Amílcar Cabral (CIDAC) in Lisbon. The research is based on primary sources (oral history) and archival research at the International Institute of Social History (IISH) in Amsterdam, the Centro de Documentação 25 de Abril, Universidade de Coimbra, and the CIDAC, Lisbon.

Key words: solidarity; colonial wars; dictatorship; Portugal and The Netherlands.

Recibido: 29 de febrero de 2020 Aceptado: 24 de agosto de 2020 Publicado: 23 de diciembre de 2020 
T a segunda guerra mundial y la subsiguiente guerra fría afectaron a EuLropa, pero, tal vez, influyó en mayor grado en los países de África, América Latina y Asia. Los movimientos de independencia y guerras coloniales transformaron esos continentes en escenarios sanguinarios durante años y en algunos casos hasta décadas.

China e India, los dos países más poblados del mundo, adquirieron su soberanía territorial a finales de los años cuarenta. La mayoría de los países colonizadores europeos enviaron ejércitos contrainsurgentes para aniquilar los movimientos de liberación calificándolos como "terroristas". Sin embargo, y sin excepción, esas guerras coloniales trajeron consigo la disolución de los imperios ultramarinos de Gran Bretaña, Francia, los Países Bajos, Bélgica y Portugal. Por ejemplo, Indonesia se declaró independiente en 1945 y, tras dos campañas "policiales", los Países Bajos tuvieron que reconocerla. Vietnam, a su vez, venció en sendas guerras a Francia en 1954 y a Estados Unidos en 1975.

En 1945 había solamente tres países africanos independientes: Etiopia, Liberia y África del Sur. Entre 1951 y 1960 gran parte de las anteriores colonias europeas en el continente se independizaron, y el resto lo fue consiguiendo en las dos décadas posteriores: Argelia y Congo-Zaire lo lograron tras largas y cruentas guerras; el Sahara Occidental se declaró independiente, pero fue forzosamente incorporado en Marruecos en 1975; Namibia, excolonia alemana, había sido administrada por África del Sur después de la primera guerra mundial y no consiguió su independencia hasta 1988; la colonia británica de Rodesia se autoproclamó independiente en 1975, pero no fue hasta 1980 y tras una larga guerra de guerrillas, que adquirió su independencia oficial y cambió su nombre por Zimbabue.

Portugal era una potencia colonial europea que glorificaba la "unidad territorial" de la metrópoli y sus "provincias ultramarinas". Formalmente administraba cinco colonias en África: Angola, Mozambique, Guinea-Bissau, Cabo Verde y São Tomas y Vicente. Además, poseía territorios ultramarinos en la "India portuguesa" que fueron anexionados por la India en 1961. La ciudad de Macao fue gobernada por los portugueses hasta su desmilitarización en 1975 y su traspaso definitivo a China en 1999.

La ideología oficialista del régimen salazarista, una dictadura católico-fascista, era de un "Portugal indivisible". En tres de las cinco colonias africanas, Portugal llevó a cabo una guerra contrainsurgente contra diferentes movimientos de liberación, en la que fue apoyado, política y militarmente, por Rodesia y África del Sur. Como se verá, el régimen se desangró militar- 
mente en una guerra colonial. A causa de ello, oficiales del ejército realizaron en 1974 un golpe militar en Lisboa con el que reestablecieron la democracia en Portugal y aceleraron el proceso de descolonización en África.

En este artículo se desarrollará un caso singular de solidaridad entre el Angola Comité de Holanda, dedicado a la solidaridad con los movimientos insurgentes, y el movimiento de la izquierda católica en Portugal, originalmente sin nombre, que fue oficialmente creado en 1974 como la oNG Centro de Intervenção para o Desenvolvimento Amílcar Cabral (CIDAC). ${ }^{1}$ La investigación surgió con base en fuentes primarias, tanto entrevistas como documentación en archivos públicos y privados. En este caso se ha consultado documentación en el International Institute of Social History (IISH) en Amsterdam, el Centro de Documentación 25 de Abril (CD25A) en Coimbra y el cidac en Lisboa.

\section{LA EMERGENCIA DE LA SOLIDARIDAD CON EL TERCER MUNDO EN HOLANDA}

Durante las primeras décadas del siglo xx, en Holanda surgieron partidos políticos confesionales (dos protestantes y uno católico) e ideológicos (socialistas y liberales), con ramificaciones en toda la sociedad y casi todos los ambientes de la vida diaria. Los católicos se casaron con católicos, y sus hijos fueron educados en escuelas de curas, monjas o frailes. Los trabajadores católicos eran miembros de sindicatos católicos. Se leía periódicos católicos. Se escuchaba solamente la radio católica. Los amigos eran católicos. El médico era católico. Se compraba en tiendas católicas. Los domingos se instruía en la iglesia sobre el comportamiento católico apropiado. Los obispos aconsejaban públicamente votar por el partido católico que en el parlamento era liderado por un cura.

Políticamente, las elites negociaron acuerdos para formar gobiernos de coalición. Este sistema funcionó casi ininterrumpidamente hasta los años sesenta. A mediados de esta década una "revolución cultural" en el país des-

${ }^{1}$ Muskens (2014) es el autor holandés que documentó la evolución de todos los movimientos contra el sistema de apartheid y las guerras coloniales de África del Sur y de Portugal, a su vez Kuitenbrouwer (1994) documentó el origen y la evolución de los movimientos pro-Tercer Mundo en Holanda, y Van Beurden y Huinder (1996) escribió la historia del Angola Comité. Se utilizó también el libro Bosgra et al. (2005) para los movimientos de solidaridad con Mozambique y KZA (1981) para el Angola Comité. 
integró el sistema confesional. La membresía de las iglesias se redujo aceleradamente y siguió decreciendo en décadas posteriores. En 2016, el 68\% de los holandeses indicó que no pertenecía a ninguna denominación religiosa (Bernts y Berghuis, 2016). La desconfesionalización coincidió con la mayoría de edad de la generación del baby boom posterior a la segunda guerra mundial. Como en los países de Europa Occidental, fue una generación crítica que ocupó universidades, organizó asambleas y mítines contra el establishment; que observó los movimientos sociales del resto del mundo y en la cual impactaron los movimientos de liberación en América Latina, África y Asia del periodo. La guerra en Vietnam, el gobierno de apartheid en África del Sur, Namibia y Rodesia, y los gobiernos revolucionarios Cuba y Nicaragua contaron con gran simpatía. Fue, en definitiva, una generación antimilitarista, anticolonialista y que abrazaba opciones progresistas.

Desde los años cincuenta la sociedad holandesa fue cambiando sus posiciones con respecto a los movimientos de liberación, el colonialismo e incluso la sociedad de apartheid. Fue un cambio desde abajo, no propiciado por la élite política. Esta, en líneas generales, se aliaba con las posiciones de Estados Unidos en temas internacionales; algunos partidos como el socialdemócrata eran anticomunistas, mientras que los socialcristianos, en el gobierno ininterrumpidamente desde 1945 y hasta 1994, siguieron las directrices de Washington. ${ }^{2}$ Los primeros políticos que se declararon en contra del apartheid fueron la ministra católica Marga Klompé y después el ministro socialdemócrata de cooperación internacional Jan Pronk. También se manifestaron a favor de los movimientos de liberación, la iniciativa proliberación y contra las guerras coloniales. En general, la oposición extraparlamentaria contó con el apoyo de estos dos ministros para llevar a cabo sus campañas.

El cambio, por tanto, se dio en la sociedad holandesa y en sus estructuras asociativas a diversos niveles: social, religioso o de cooperación, entre otros. Los movimientos sindicales, y muchos municipios, levantaron la bandera de protesta en contra del racismo y el sistema de apartheid. Crecieron cinco movimientos de cierto significado (al que cabe sumar el más pequeño dirigido por el Partido Comunista) en apoyo de movimientos antirracistas en África del Sur y de solidaridad con los movimientos de independencia en las colonias

${ }^{2}$ El exdiplomático ultraconservador Jozef Luns del partido católico fue el primer canciller holandés tras la segunda guerra mundial (1946-1971) y más tarde presidente de la OTAN (1971-1984). 
portuguesas. Sus líneas de trabajo fueron buscar fondos de donaciones y la concientización política. Sus líderes tuvieron un origen diverso: estudiantes, profesores de primaria y secundaria, catedráticos, religiosos, sindicalistas (inclusive del sindicato de militares), periodistas indignados (especialmente de las emisoras públicas). En un periodo de dos décadas lograron cambiar profundamente la opinión pública y hasta la de las cúpulas directivas de la Royal Dutch Shell, de grandes consorcios de supermercados, de la KLM y de otras empresas y asociaciones empresariales que originalmente se habían opuesto a actividades contra Portugal (hasta 1974) y contra África del Sur (hasta 1990). ${ }^{3}$

Este cambio fue respaldado por las iglesias luteranas, calvinistas y católicas. Hasta la reina Juliana donó en 1971 un dinero a los movimientos de protesta, "como persona y no como jefe de estado" (Muskens 2014, pp. 18, 352-353). En África del Sur el pastor Beyers Naudé, originalmente miembro del Afrikaanse Broederbond, los defensores más duros del apartheid, se distanció de aquel grupo y fundó el Christelijk Instituut dentro del Nederduits Gereformeerde Kerk. Beyers Naudé llegó a ser un personaje prominente contra el régimen de apartheid, lo que le conllevo la expulsión de la Iglesia surafricana. La Universidad Libre (protestante) de Ámsterdam, reaccionó y le otorgó un doctorado honoris causa en teología en 1972. En esos años se formó en el seno de la comunidad protestante holandesa un grupo de trabajo denominado "KAIROs" ("el momento oportuno" en griego eclesiástico), que rápidamente creció hasta convertirse en un movimiento de gran influencia que recogió fondos otorgados por los creyentes en favor de movimientos antirracistas y de liberación en África Austral.

Dentro de la Iglesia católica se originó un grupo semejante, Pax Christi. En junio de 1970 el Papa Paulo VI recibió en el Vaticano a Agostinho Neto, Marcelino dos Santos y Amílcar Cabral en su calidad de líderes del MPLA (Angola), rRelimo (Mozambique) e PAIGc (Guinea-Bissau y Cabo Verde), gesto que fortaleció la legitimidad de aquellos movimientos de liberación. ${ }^{4} \mathrm{El}$

${ }^{3}$ Holanda había mantenido lazos estrechos con África del Sur. Compartían la religión y la lengua, el afrikaans se distanció del holandés a partir del siglo xviII. Los Boeren son descendientes de los colonizadores holandeses. Originalmente el término era equivalente a "agricultores", pero con el tiempo se convirtió en una indicación étnica.

${ }^{4}$ MPLA, Movimento Popular de Libertação de Angola; frelimo, Frente de Libertação de Moçambique; PAIgc, Partido Africano da Independência de Guiné e Cabo Verde. En Angola operaban también la União Nacional para a Independência Total de Angola (UNITA) y el Frente Nacional de Libertação de Angola (FNLA) en plena competencia y regularmente en combate con el MPLA. 
Consejo Mundial de Iglesias ya antes había dado pruebas de simpatía por la causa con declaraciones de condena el sistema de apartheid.

Las principales organizaciones implicadas en el sistema bilateral de cooperación internacional fueron fundaciones como CEBEMO/CORDAID (católica), ICCO (protestante), NOviB/oxfAM (socialdemócrata) e HIVos (humanista), quienes en los años setenta, junto con otras organizaciones, comenzaron a recibir financiamiento gubernamental. ${ }^{5}$ También emergieron otros movimientos como el Boycot Outspan Actie en contra de la compra de frutas de África del Sur y de café angolano; el Anti-Apartheids Beweging Nederland (AABN), en el cual participaron miembros y simpatizantes comunistas; o el Medisch Komitee Angola, grupo de médicos tropicales auspiciado desde el propio Partido Comunista. Este último estuvo formado por idealistas que trabajaron con un salario mínimo. Tras su ruptura por disputas doctrinarias sobre la ortodoxia necesaria para llevar a cabo su labor, algunos de los médicos fueron "adoptados" y a veces nutridos por sus colegas cubanos que trabajaron en la misma región (Chabot, 2013). ${ }^{6}$ En general todas aquellas organizaciones estuvieron dirigidas por voluntarios que recibieron una retribución simbólica. La más exitosa de todas ellas, el Angola Comité-Komité Zuidelijk Africa, será objeto de este artículo y por tanto analizado en secciones posteriores.

\section{EL RÉGIMEN SALAZARISTA PORTUGUÉS Y LAS GUERRAS COLONIALES}

De los cuatro regímenes directamente asociados al fascismo europeo (Alemania nazi, Italia fascista, España franquista y el Estado Novo en Portugal), el régimen de Salazar primero (1933-1968) y de Caetano (1968-1974, tras la enfermedad del primero) se presentaba como el más "pacífico" y "civilizado"

${ }^{5}$ CEBEMo (1961) era la organización católica para la asistencia humanitaria al Tercer Mundo. Después de fusionarse con otras organizaciones, cambió el nombre en CORDAID. ICCO (1964) es la Comisión Coordinadora Intereclesiástica (protestante) para la cooperación al desarrollo. NOVIB (1956) era la Organización Holandesa para la Asistencia Internacional fundada por sacerdotes y pastores protestantes sin vínculo directo religioso. El primer Premio Nobel en economía Jan Tinbergen fue miembro fundador. En 2006 cambió su nombre en NOviB/oxFAM cuando ya desde 1994 se había vinculado a oxfAM International. HIvos (1968) fue fundada por la Asociación Humanista y trabaja mediante oficinas regionales en África, Asia y América Latina.

${ }^{6}$ Entrevista al señor J. Chabot, realizada por Dirk Kruijt, el 7 de marzo de 2017. Utrecht, Holanda. 
(Almeida, 2008; Pinto y Rezola, 2007). Su longevidad residió, entre otras claves, en los lazos estrechos establecidos con la Iglesia católica en el concordato de 1940, por una parte; y en el control social y político a través de su temida policía política, la Policía Internacional de Defesa do Estado (PIDE), que disponía de centros de interrogación y tortura, cárceles para presos políticos y un campo de concentración en Cabo Verde. Ambos elementos permitieron que Salazar, exseminarista, austero, célibe, soltero e íntimo amigo del Cardenal Patriarca de Lisboa Manuel Cerejeira, dominase durante décadas un pequeño país con un gran imperio colonial, el cual nunca visitó.

Angola fue para Portugal lo que la India para Gran Bretaña, Argelia para Francia e Indonesia para los Países Bajos. Se trataba de un sistema colonial clásico, con la mayoría de los colonos portugueses establecidos en la capital, Luanda, con la ciudadanía restringida a los blancos y a los assimilados (mestizos y occidentalizados), y con una posición inferior para los demás habitantes regida por el Estatuto do indígena. El sistema represivo de la policía política en las colonias fue la Dirección-General de Seguridad (DGs), que funcionó como aparato de inteligencia y represión.

La oposición contra el régimen fascista se manifestó en las colonias y en Portugal de manera diferente. En las colonias, primero en Angola y casi inmediatamente en Mozambique y Guinea-Bissau, emergieron varios movimientos de resistencia y de lucha anticolonial. En 1961 se había creado la Conferência das Organizações Nacionalistas das Colonias Portugueses (CON$\mathrm{CP}$ ) en Casablanca, cuyo secretario sería Marcelino dos Santos, del Frelimo. ${ }^{7}$ La CONCP fue la plataforma de intercambio de los movimientos de guerrilla en Angola (con tres movimientos en plena rivalidad: MPLA, UNITA y FNLA), Mozambique (frelimo), Guinea-Bissau junto con Cabo Verde (pAIGC) y un pequeño movimiento en São Tomé y Vicente. También Timor del Este tenía su propio comité para la liberación.

Todos estos movimientos nacieron entre fines de los cincuenta y primeros sesenta al calor del movimiento de descolonización general en el continente africano, encabezado por Argelia (1962). Este país no sólo fue ejemplo por su lucha contra los franceses, sino que desde pronto se convirtió en santuario para otros movimientos de liberación, centro de contacto internacional, y de vínculo con otros movimientos y países de otros continentes. En

${ }^{7}$ Fallecido el día 11 de febrero de 2020, el diario Novo Jornal publicó una conmemoración de la fundación del concr el 14 de febrero de 2020. 
1963 Argelia formalizó un pacto de intercambio de inteligencia y cooperación con Cuba para el apoyo de movimientos africanos (Kruijt, 2017, p. 83). En el mismo año se creó en Adís Abeba la Organización de Unidad Africana (oUA) por una treintena de presidentes y jefes de gobierno africanos, que apoyaba y reconocía los movimientos luso-africanos.

Muchos de los líderes de los movimientos de liberación nacional se conocían entre ellos. Habían pasado tiempo en la Casa dos Estudantes do Império (CEI) en Lisboa, escuela para los futuros "líderes assimilados". Muchos habían sido miembros o simpatizantes del Partido Comunista Português, clandestino pero influyente como movimiento opositor al régimen. Futuros presidentes y ministros luso-africanos recibieron cursos en París y Moscú. Algunos participaron en la Conferencia Tricontinental celebrada en La Habana en 1966, de donde obtuvieron los contactos que sirvieron para recibir el apoyo de Cuba a los movimientos de liberación en Guinea-Bissau y Angola (cuyas misiones militares en el último país fueron legitimadas por la oUA).

La respuesta de Portugal a los movimientos y organizaciones anticolonialistas fue represiva. Su causa también recibió apoyo internacional: oficiales portugueses siguieron cursos de lucha antisubversiva en Francia y Argelia en los primeros sesenta; y, en julio de 1961, firmó un pacto de asistencia mutua con África del Sur y con Rodesia. En aquel año inició una guerra colonial antisubversiva que pronto degeneró en una guerra sucia con tropas especiales de las que una buena parte fueron negros; y tropas paramilitares, As Flechas, y de autodefensa militarizada de los residentes blancos (Gomes y Alfonso, 2009a). ${ }^{8}$

El costo del conflicto fue impactante tanto para los países africanos como para Portugal. En los trece años de guerra fueron movilizados 820000 soldados portugueses, de los cuales murieron 8830 y unos 30000 resultaron heridos y mutilados. En África del Sur fueron movilizados unos 600000 soldados blancos y negros para lo que llamaron las Frontier Wars Up North, "guerras de la frontera hacia el norte". Carecemos de estimaciones sólidas sobre el número de muertos, heridos, mutilados y desaparecidos en las colonias (Guerra, 2009; Wessels, 2017). Gran parte de las tropas portuguesas fueron reclu-

${ }^{8}$ Acerca de las matanzas cometidas, véanse los trabajos de los historiadores, militares y periodistas sudafricanos Liebenberg, Risquet y Shubin (2015), Venter (2015), y Waals (2011). Los primeros militantes de As Flechas eran nómadas-cazadores Bosquimanos (derivado de "Boesman" en Afrikaans, "Bush man" en inglés), pigmeos pobladores originarios que vivían en las regiones desérticas en África Austral. No podían cargar armamiento pesado, pero eran excelentes cazadores que usaban flechas venenosas, cosa que atemorizaba a los guerrilleros. 
tadas de los habitantes negros en las colonias. Los registros oficiales hablan de "tropas reclutadas localmente" en Angola, Mozambique y Guinea-Bissau. Coelho, historiador mozambiqueño, estimó un total de 87274 portugueses en 1973 y 61816 angolanos, mozambiqueños y guineanos, 42\% de las tropas totales coloniales (Coelho, 2015, pp. 477-478). Otras fuentes presentan números mayores: alrededor de 1400000 soldados en total, de los cuales 400000 fueron reclutados localmente. Al final de la guerra, casi la mitad de los soldados eran africanos (Cruz Rodrigues, 2013). De su suerte posterior no se sabe nada. Venter (2015, p. 250) menciona que tras la independencia en Guinea-Bissau en 1975, a pesar del convenio de amnistía, soldados, sargentos y oficiales de las tropas especiales portuguesas fueron arrestados y ejecutados. Este hecho ha sido confirmado por Nóbrega (2003, pp. 214-206). El presidente Luis Cabral explicó a Nóbrega en dos entrevistas que los portugueses entregaron los listados a la PIDE para identificar los Comandos Africanos (Rodrigues, 1995). En total, las guerras coloniales costaron 21700000 euros. En 1960 los gastos militares representaron 3\% del producto interno bruto (РІB), 6\% entre 1966 y 1971, y 5\% de 1972 a 1974. Entre 1961 y 1974 los "gastos miliares del ultramar" representaron 21\% del presupuesto nacional (Ferraz, 2019, pp. 4 y 8 ).

\section{RESISTENCIA Y CAMBIO DE RÉGIMEN EN PORTUGAL}

En Portugal también hubo movimientos de resistencia militar y civil. Muchos de los que por su edad podían ser reclutados para la guerra colonial salieron del país clandestinamente, $y$ una vez en el exterior se unieron a los refugiados económicos. Se estima que el número total fue de alrededor de 1500000 personas, cifra que incluye también un número considerable de soldados y oficiales portugueses reclutados (en la terminología oficial "milicianos") que desertaron (Guerra, 2009). ${ }^{9}$

El año 1968 fue el año de los movimientos de protesta estudiantil en Europa. Como había de esperar, los ecos llegaron también a España franquista y a Portugal salazarista. En Coímbra, Lisboa y Oporto surgieron protestas estudiantiles que llegaron a ocupar las universidades. Muchos de ellos pagaron

9 Entrevista al señor Fernancio Morais, realizada por Dirk Kruijt, el 18 de diciembre de 2019. Lisboa, Portugal; Entrevista al señor José Dias, realizada por Dirk Kruijt, el 19 de febrero de 2020. Lisboa, Portugal. 
su activismo estudiantil siendo enviados como soldados y oficiales milicianos a la guerra; en el caso de tener estudios alcanzaron a ser teniente o capitán miliciano. ${ }^{10}$ Sus ideas influyeron sosegadamente a algunos de los principales oficiales regulares que iniciaron en 1974 la Revolución de los Claveles. ${ }^{11}$

Además de entre los estudiantes, los movimientos de oposición a la dictadura fueron variados. Hay constancia de que entre los miembros del Partido Comunista se desarrollaron movimientos clandestinos de guerrilla en Portugal (Carmo, 2017). Más allá de esos grupos, el Partido Comunista Portugués fue un opositor civil tenaz. Muchos trabajadores en los centros urbanos e industriales fueron simpatizantes de los grupos clandestinos. Aparentemente el PCP dio la consigna a sus militantes de no desertar hacia Europa, sino unirse a las tropas en las colonias e intentar vincularse con los movimientos de liberación. ${ }^{12}$

Por su parte, el "catolicismo progresista" creciente a partir de la segunda mitad de los años sesenta comenzó a influir en segmentos de la población que hasta este momento no habían sido opositores. Divulgaban manuscritos clandestinos, organizaban conferencias y en 1972 llegaron a ocupar la Capela do Rato en el centro de Lisboa. En esa ocasión la PIDE intervino y arrestó a 60 personas entre laicos y sacerdotes. Algunos de ellos llegaron después de 1974 a posiciones claves en el estado. El abogado Jorge Sampaio, por ejemplo, llegó a ser electo como presidente de la República entre 1996-2006.

Del lado militar también hubo oposición e incluso entre la cúpula militar surgieron algunas voces alternativas. En 1958 un general progresista, Humberto da Silva Delgado, se presentó como candidato para presidente de la República en contra del candidato del régimen. Las elecciones fueron amañadas y tuvo que exiliarse en España, donde fue asesinado por la PIDE en 1965. En enero de 1961 el exmilitar Henrique Galvão y sus compañeros asaltaron el barco turístico Santa María, desde él emitieron mensajes contra el fascismo de Salazar antes de buscar refugio en Brasil, donde soltaron los pasajeros y encontraron asilo. En abril de 1961 el ministro de defensa, Botelho Moniz, y su secretario de Estado, Costa Gomes, pusieron de manifiesto su opinión de que la solución

10 Fernancio Morais, entrevista citada; José Dias, entrevista citada; Entrevista al señor Jorge Conceição, realizada por Dirk Kruijt, el 7 de febrero de 2020. Lisboa, Portugal.

${ }^{11}$ Entrevista a Fernando José Salgeira Maio, realizada por la historiadora María Manuela Cruzeiro, 11 de septiembre de 2018. El autor escuchó la grabación en octubre de 2017 en el CD25A en Coimbra, Portugal.

${ }^{12}$ José Dias, entrevista citada. 
debería ser política y no una guerra contrasubversiva, por lo que fueron destituidos. Costa Gomes fue más tarde comandante-en-jefe en Mozambique y en Angola. Dentro de los círculos militares gozó de un gran prestigio y llegó a ser presidente de la República durante la Revolución de los Claveles.

Dentro del grupo de oficiales subalternos, tenientes, capitanes y algunos mayores, se oyeron quejas por la mala calidad del armamento, los muertos, heridos y masacres, la arrogancia de los colonizadores locales y el mal trato a la población negra. ${ }^{13}$ Tampoco veían una solución pronta del conflicto, y algunos oficiales incluso lo expresaron públicamente, caso del entonces capitán Ernesto de Melo Antunes (más adelante uno de los actores claves en la Revolución de los Claveles y del proceso de descolonización):

[...] el régimen es, de facto, una dictadura militar [...]. El Estado Mayor está mayoritariamente constituido por elementos reaccionarios y conservadores, verdaderos burócratas [...] mientras tanto los oficiales luchamos para los intereses de los tiburones que se enriquecen a costa del esfuerzo del militar colonial. [...]. La solución puede ser solamente política, militarmente nunca vamos a ganar esa guerra [que] está sangrando la economía de nuestro país sacrificando miles de muertos y mutilados (Gomes y Alfonso, 2009b, pp. 11-15).

En 1973 se reunieron unos ciento treinta y seis oficiales en un lugar secreto para discutir sobre un problema laboral: la equivalencia de oficiales profesionales y de oficiales milicianos. Una vez reunidos, el tema central pasó a ser la guerra interminable sin posibilidad de ganar, llegando a un consenso sobre la necesidad de deshacerse del régimen fascista, terminar la guerra, restablecer la democracia e independizar las colonias. El resultado fue la creación del Movimento das Forças Armadas (MFA), que se expandió a otras ramas del ejército, y se estructuró en torno a una comisión militar liderada por el mayor Otelo de Saraiva, y una comisión política por el mayor Melo Antunes. Algunos oficiales progresistas de mayor rango fueron contactados, como el coronel Vasco Gonçalves, quien dirigiría cinco de los seis gobiernos entre 1974 y 1976.

El golpe de los militares disidentes se dio el 25 de abril de 1974, pronto apoyado por la población, que salió a las calles, subió en los tanques y comen-

${ }^{13}$ El ingeniero militar miliciano Jorge Conceição, que sirvió en Mozambique, recuerda que la elite colonial blanca en el elegante Country Club tiraba piedras a los negros y se quejaba sobre el ruido que realizaban los militares portugueses. Señor Jorge Conceição, entrevista citada. 
zó a repartir entre los militares alimentos y los claveles que dieron nombre a la "Revolución de los Claveles". Los golpistas propusieron al general Spínola, recientemente despedido por el gobierno. En los dos años siguientes, durante los gobiernos transitorios cívico-militares, se crearon nuevas estructuras políticas, sociales y económicas, y se realizaron grandes reformas $;{ }^{14}$ aunque también hubo divisiones dentro de las filas militares, y hasta intentos de golpes de Estado por parte de la derecha y de la izquierda militar (Chilcote, 2012, pp. 89-192; Maxwell, 2010).

Entre 1974 y 1976 también se llevó a cabo el proceso de descolonización. Dos de los ministros de Relaciones Exteriores del bienio desempeñaron un papel sustantivo: Soares y Melo Antunes (Correia, 2017; Guerra, 2009; Marques, 2013). Soares no era partidario de la independencia de Cabo Verde, y se hizo acompañar por asesores militares durante sus negociaciones con los movimientos de liberación. De hecho, fue Melo Antunes quien como ministro sin cartera redactó la Ley de Descolonización que organizó el proceso de descolonización. Antunes gozaba de autoridad y respeto entre los líderes de los movimientos de liberación, al punto que el periódico oficial de Mozambique Noticias lo calificó como "el interlocutor favorito de FRELIMo, del MPLS y del PAIGC". ${ }^{15}$

Con todo, el proceso de negociación de la independencia no fue fácil. Hubo opositores externos, caso de políticos y militares en Rodesia, África del Sur y Zaire, que cedieron su territorio para entrenar fuerzas militares, paramilitares y mercenarias que atacasen a los movimientos de liberación (Correia, 2017, pp. 399 y 475). Los propios movimientos independentistas no eran monolíticos, y los intereses de sus facciones no siempre fueron coincidentes, sobre todo en el caso angolano, donde los tres movimientos, MPLA, ${ }^{16}$ UNITA y FNLA eran también enemigos. La complicación de las negociaciones en Angola con tantos actores e intereses contrapuestos motivaron el viaje de Melo Antunes a Luanda el 15 de julio de 1975 para "por última vez tratar de terminar con los combates sangrientos dentro de Angola, que el día 11 de noviembre de

${ }_{14}$ Acerca de la principal reforma, la Agraria, véase Correia (2018), quien fue comandante militar en el Alentejo durante esos años. Sobre los movimientos populares durante los dos años de reformas, véase Varela (2018).

${ }^{15}$ Noticias, Mozambique, 6 de abril de 1975. Este mismo periódico mencionó los "saludos revolucionarios” del ministro-presidente Vasco Gonçalves por el día de la independencia (el 21 de junio de 2975). Noticias, Mozambique, 29 de junio de 1975.

${ }_{16}$ Apoyado militarmente por Cuba (George, 2005). 
1975 será independiente". Anunció que eventualmente las tropas portuguesas deberían intervenir para terminar las masacres. ${ }^{17}$

En Guinea-Bissau el PAIGC llegó a controlar territorios considerables, de modo que unilateralmente declaró la independencia nacional el día 24 de septiembre de 1973, hecho que fue reconocido inmediatamente por 63 países. Fue declarada formalmente independiente por Portugal en 1974. Siguieron Mozambique, Cabo Verde São Tomé y Príncipe, todos en 1975 y todos como Repúblicas Populares. La República Popular de Angola fue declarada independiente el 11 de noviembre de 1975. Quienes asistieron a la ceremonia escucharon los cañones de las tropas de África del Sur. ${ }^{18}$ En este momento el MPLA controló solamente el "corredor marxista" costeño fue protegido por las tropas cubanas y del MPLA.

Rápidamente tras el cese del fuego se inició un proceso de emigración masiva de unos 471000 residentes blancos portugueses desde las colonias hacía la metrópoli. En el censo portugués de 1981 hay anotados 290504 "retornados" de Angola (61\%), 158945 de Mozambique (34\%) y 21978 de las otras tres colonias (5\%) (Pires, 2003, pp. 190-200). Portugal retiró todos sus solados, 100 500, en un año después de la independencia. De repente, los nuevos países se encontraron con una desastrosa falta de trabajadores cualificados: médicos, técnicos, académicos, administradores, funcionarios públicos, profesores de primaria y cualquier empleo que requiriese un grado avanzado de instrucción.

\section{EL ANGOLA COMITÉ, EL CIDAC Y LA PRIMERA ASISTENCIA TÉCNICA A LAS COLONIAS}

En 1961 grupos de estudiantes se manifestaron ante el Palacio de Justicia de Ámsterdam en defensa de un holandés y un griego que iban a ser juzgados por falsificar documentos y dinero en favor del Frente de Liberación de Argelia (FLA). El holandés condenado fue Sal Santen, yerno de Henk Sneevliet, fundador del Partido Comunista de China y de Indonesia en 1921, además de ser el primer fusilado por los nazis cuando tomaron Holanda. Entre los manifestantes había dos estudiantes, Sietse Bosgra y Trineke Weijdema, quie-

\footnotetext{
${ }^{17}$ Noticias, Mozambique, 15 de julio de 1975.

${ }^{18}$ Entrevista al señor Paul Staal, realizada por Dirk Kruijt, el 28 de noviembre de 2018. Amsterdam, Holanda.
} 
nes unos años después lideraron el Angola Comité. Como muchos de su generación eran antimilitaristas y anticolonialistas, indignados con las guerras holandesas y la argelina se solidarizaron con otros movimientos de liberación y fundaron el Argelia Comité (Brothers from the West/Irmãos do Ocidente, 2005). ${ }^{19}$

En 1961 el mencionado asalto de Henrique Galvão y sus compañeros al barco Santa María en pleno Atlántico llamó la atención en Europa sobre la violencia en las colonias portugueses en África. Casi inmediatamente Bosgra y otros crearon un comité informal que llamaron Angola Comité, siguiendo el ejemplo del Comité pro-Algeria, para informar, distribuir volantes y buscar fondos. Originalmente emprendieron acciones muy llamativas como perturbar marchas militares de la OTAN en donde participaban soldados portugueses; además organizaron concentraciones ante bancos y edificios públicos. Trabajaron con voluntarios, pero, aunque no tuvieron trabajadores profesionales, la dedicación fue plena. Incluso la dirección postal era la particular de uno de sus miembros. En 1971 consiguieron pagar a los primeros tres colaboradores y alquilar un espacio de trabajo (KZA, 1981, p. 5). Uno de sus libros sobre las guerras coloniales llegó a un tiraje de 12000 ejemplares.

Al comienzo su orientación fue tratar de captar la simpatía de los movimientos de todo el espectro de izquierdas, el medio ambiente que conocían. Sin embargo, en base de discusiones con líderes del FrELIMo, fueron convencidos de la necesidad de adquirir un apoyo más amplio de un público más extenso, cubriendo gran parte del centro, centro-izquierda y centro-derecha. Tras la modificación de su estrategia en un par de años gozaron con gran simpatía del público. Movilizaron sindicatos y periodistas, sobre todo los de la radio y $\mathrm{TV}$ de las emisoras públicas, redactores de periódicos y semanarios, y cooperaron con instituciones semejantes como el Netherlands Institute for Southern Africa (NIZA) y el Eduardo Mondlane Stichting. En 1964 Eduardo Mondlane y su esposa Janet, del frelimo, llegaron a Holanda. Durante su estancia fueron invitados por la radio y $\mathrm{TV}$, realizaron encuentros con líderes sindicales y comités de solidaridad, además las iglesias católicas y protestantes y las universidades les invitaron a dar presentaciones.

Esta sería una estrategia permanente: invitar interlocutores de cierta estatura desde las colonias o de los territorios controlados por los movimientos de liberación, y organizar eventos. Por ello, invitaron a desertores portu-

19 Brothers from the West/Irmãos do Ocidente (2005), oficialmente no tiene autor, pero fue escrito por Bosgra casi por completo. 
gueses, a misioneros expulsados de los territorios de ultramar, a monjas que habían sido testigos de las masacres, y a los pocos obispos portugueses (de Porto, de Beira y de Nampula en las colonias) que públicamente se opusieran al régimen. Así, lograron obtener la confianza de sacerdotes ingleses, españoles y holandeses destinados en la África Lusófona que, a diferencia con la jerarquía portuguesa, estaban dispuestos a hablar y denunciar las masacres cometidas por las tropas y mercenarios.

Bosgra y los suyos consiguieron tener una influencia mucho mayor de la que se podía esperar de un grupo de voluntarios. Además, mostraron una enorme habilidad para organizar campañas que se tradujeron en donaciones sustantivas. El Angola Comité tuvo por aquel entonces una revista con 7000 suscriptores, 40000 donantes estables, y había aprendido cómo realizar campañas mediáticas. Financiaba viajes de periodistas que clandestinamente se entrevistaron con opositores del régimen. Entre otros invitó a periodistas británicos de The Guardian o del Financial Times, equipos de TV holandesa o de otros países europeos para reportajes en las colonias antes y después de su independencia. ${ }^{20}$

Paul Staal, otro de los miembros claves, comenzó a actuar como el embajador itinerante del Angola Comité. ${ }^{21}$ Viajaba con cierta frecuencia por los territorios liberados en Guinea-Bissau, Mozambique y Angola, ${ }^{22}$ alojándose en casa de religiosos que lo pusieron en contacto con guerrilleros locales, sobre todo en los territorios liberados de Guinea-Bissau donde ya no había tropas portuguesas. Estuvo presente durante la noche de la independencia de Angola con el periodista-escritor polaco Kapuscinski (2001), cuyo Another day of life llegó a ser un relato clásico sobre los días ansiosos de esa nación en el momento de su independencia en medio de una guerra civil. Juntos observaron los Tupolevs aterrizando con las tropas cubanas que fueron llevados inmediatamente para el frente de combate.

Entre 1973 y 1977 Holanda fue gobernada por el gabinete progresista de Den Uyl y a partir de ese momento el Angola Comité accedió a fondos públicos de la cooperación internacional oficial. Pero seguía manteniendo su propia red de donantes para poder moverse de manera independiente. Me-

20 Señor Paul Staal, entrevista citada.

${ }^{21}$ Señor Paul Staal, entrevista citada; Entrevista al señor Ernst Schade, realizada por Dirk Kruijt, el 28 de agosto de 2018. Lisboa, Portugal.

${ }^{22}$ Noticias de Angola, 15 de mayo y 17 de noviembre de 1976. 
diante contactos en Portugal, básicamente con la resistencia civil de católicos progresistas, y luego en África Austral, lograron transferir fondos privados a los movimientos de liberación. Consiguieron que periodistas pidiesen vacaciones para marcharse a África e instalar estudios de emisión profesional para los movimientos de liberación.

Staal, que anteriormente había sido director de relaciones internacionales de la Universidad de Utrecht, comenzó a viajar sistemáticamente a Portugal y sus colonias, a veces utilizando seudónimos, pero sin haber estado en la mira de la PIDE. Se relacionó con el grupo de intelectuales y líderes católicos del Capelo de Rato en Lisboa y de la Comissão Justiça e Paz en Oporto (Teotónio Pereira, 2004, p. 19). Estos por su parte buscaron canales para difundir en Portugal y en el exterior la persecución realizada por el régimen salazarista, la fuga de los desertores, la complicidad de la jerarquía católica, y, sobre todo, la situación de la guerra colonial, las masacres realizadas por las tropas especiales y las invasiones desde Zaire, Rodesia y África del Sur.

En 1974 un grupo de laicos, curas y monjas, cuyos líderes eran el arquitecto Nuno Teotónio Pereira y su mujer Natalia, el catedrático y filósofo Luis Moita, el activista José Dias en Coimbra y Luisa Teotónio Pereira, hija de Teotónio y Natalia, fueron los fundadores de la ONG-CIDAC, que guarda en la actualidad el archivo de la clandestinidad (Matías, 2004, p. 25). Teotónio Pereira y Luis Moita fueron liberados de la cárcel el 27 de abril de 1974, dos días después de la Revolución de los Claveles.

Unos años antes este grupo había empezado a editar publicaciones clandestinas como la serie Direito à Informação sobre encarcelamientos y opiniones censuradas. Publicaron también información sobre los movimientos de liberación en las colonias y textos de Amílcar Cabral, todavía prohibidos en Portugal. Tenían contactos con varios de sus excolegas universitarios que, castigados, habían sido mandados como oficiales milicianos a las colonias. Horrorizados, contaron la vida diaria en las colonias, las aldeas fortificadas, las masacres hechas por las tropas especiales y la "limpieza" después por otras tropas especiales. ${ }^{23}$ Algunos llegaron a citar directamente los informes militares y de inteligencia. ${ }^{24}$ Transportaron estos sobres con información sensible por medio de amigos que regresaron periódicamente a Lisboa de permiso familiar. Algunos informes clandestinos fueron publicados como BAC (1975),

23 Señor Fernancio Morais, entrevista citada.

24 Señor José Dias, 12 de septiembre de 2018 y 19 de febrero de 2020, entrevistas citadas. 
después de la Revolución de los Claveles (Matías, 2004, p. 21). ${ }^{25}$ Una copia de todos esos documentos fue llevada por Staal a Amsterdam donde el Angola Comité distribuía extractos a Amnesty International, organizaciones de la ONU, la prensa internacional y a Dar-es-Salaam donde los movimientos de liberación tenían una oficina. ${ }^{26}$

Como el Angola Comité, el cIDAc funcionaba como una organización informal, desde la casa de sus miembros, con voluntarios, sin horarios fijos y sin salario. En el sentido político, guardaron siempre su posición de no afiliación política partidaria. A medida que evolucionó y sus funciones cambiaron también lo hizo su nombre, aunque no el acrónimo: nació como Centro de Informação e Documentacão Anti-Colonial (CIDA-C); en 1977 cambió a Centro de Informação e Documentação Amílcar Cabral (CIDAC), y en 2004 se volvió a transformar en Centro de Intervenção para o Desenvolvimento Amílcar Cabral (CIDAC) (Teotónio Pereira, 2004, pp. 27, 32 y 50). El Angola Comité financió la creación formal del cIDAC con fondos obtenidos durante una campaña por radio y TV por valor de varios centenares miles de florines (KZA, 1981, p. 47). La relación entre ambas instituciones facilitó a otras organizaciones obtener recursos de la cooperación para el desarrollo holandesa (Beurden y Huider, 1996; Bosgra et al., 2005; Hendrix, 2006; Muskens, 2014). El Angola Comité también facilitó contactos con los líderes de los movimientos de liberación en las colonias, algo inédito en Portugal salazarista.

Inmediatamente después del 25 de abril de 1974, estando en la legalidad, editaron los programas y los textos populares de los movimientos políticos en las colonias, caso de discursos de Cabral y de Samora Machel. Como habían sido estrictamente prohibidos, fueron las primeras noticias en Portugal sobre lo que representaron aquellos movimientos. Le siguieron poco después un libro sobre Ginea-Bissau y textos del Frente Revolucionario de Timor-Leste (FRETELIN). También entrenaron alfabetizadores timorenses, quienes al regresar fueron masacrados por las tropas de las Fuerzas Armadas de Indonesia que invadieron la excolonia en diciembre de ese mismo año. Todavía en 1974 mandaron ropa, medicamentos y material didáctico para Mozambique. En aquel año y en 1975 instruyeron, entrenaron y mandaron

${ }^{25}$ BAC o Boletim Anti-Colonial. En la clandestinidad fueron distribuidos nueve boletines.

${ }^{26}$ José Dias, 19 de febrero de 2020, entrevista citada; Paul Staal, entrevista citada. En el International Institute of Social History se encuentran siete volúmenes de unas 250 páginas cada uno con las copias de la información militar y de inteligencia. 
los primeros profesores voluntarios de primaria a Guinea-Bissau, que había quedado casi totalmente sin personal docente educativo. El año siguiente enviaron dos grupos de docentes para la enseñanza secundaria a Cabo Verde a solicitud del gobierno de las islas.

El CIDAC fue la primera organización privada que mandó profesores y expertos voluntarios a los países recientemente independientes cuyos cuadros se habían refugiado a Portugal (Santos, 2014; Teotónio Pereira, 2004). ${ }^{27}$ En los años ochenta se profesionalizó el entrenamiento y la asistencia en materia de educación, salud pública y de gestión económica, tanto para grupos de voluntarios portugueses como para los estudiantes en Portugal procedentes de los Países Africanos de Lingua Oficial Portuguesa (PALOP). Inclusive llegaron desde otros países europeos voluntarios y cooperantes que recibieron entrenamiento en el CIDAC sobre la lengua y la cultura de las antiguas colonias. Fue la primera ONG con la que el gobierno portugués firmó un contrato plurianual para programas en África Austral. El 26 de abril de 2004 recibió de la mano de Jorge Sampaio, presidente de Portugal, la Ordem da Libertade.

\section{CONCLUSIONES}

Este artículo ha analizado el caso de una cooperación Norte-Sur con seis países involucrados: Angola, Cabo Verde, Ginea-Bissau, Mozambique, los Países Bajos y Portugal. Se ha demostrado que incluso dentro de situaciones represivas o en situaciones de guerra, organizaciones informales (el Angola Comité en Holanda y la red de católicos progresistas en Portugal que luego se transformó en el CIDAC) pueden desempeñar actividades significativas de solidaridad.

Para poder contextualizar el inicio y la evolución de esos grupos ha sido necesario esbozar los cambios producidos durante los años sesenta en Holanda y los setenta en Portugal. La independencia unilateral en 1945 y el proceso de descolonización de Indonesia había sido traumática para Holanda. Los esfuerzos de una reconquista violenta durante cuatro años terminaron con un acto de transferencia de la soberanía en diciembre de $1949 .{ }^{28}$ Desde

${ }^{27}$ Entrevista a la señora Luisa Teotónio Pereira, realizada por Dirk Kruijt, el 3 de febrero de 2020. Lisboa, Portugal.

${ }^{28}$ La colonia de Surinam se independizó en 1975 tras negociaciones sobre un monto formidable de 1600 millones de euros para la cooperación de desarrollo. Las Antillas Holandesas decidieron mantener el lazo con la metrópoli que después de largas negociaciones se disolvió en 
Holanda se enviaron 100000 soldados, 50000 voluntarios y algunos miles de militares profesionales para fortalecer los 70000 militares del Koninklijk Nederlands-Indisch Leger (KNIL), las fuerzas armadas coloniales (Oostindie, 2015). La generación de posguerra creció con profundos sentimientos antimilitaristas, de solidaridad con el Tercer Mundo y apoyo a movimientos de anti-apartheid, antifascistas y de liberación nacional. Esos sentimientos, tal vez, expresaron la posibilidad de resarcirse de su propio pasado.

En Portugal hubo dos procesos paralelos: la transformación de un régimen fascista en una democracia y el proceso de descolonización de cinco colonias en África. Portugal fue el país europeo que más tardó en dar la independencia a sus colonias. El hecho de que una generación entera se enfrentara a guerras coloniales, que no eran percibidas como suyas, contribuyó a procesos de resistencia pasiva, expresados en la emigración, y una oposición creciente contra un régimen caduco, pero fuertemente represivo. Este hecho explica también la explosión de popularidad con los militares que hicieron el golpe de 1974, además de la rapidez con que los militares en el poder aceleraron la independencia de todas sus colonias africanas, en un periodo de un año y ocho meses, incluso en Angola donde una guerra civil estalló el mismo día de su independencia.

Es interesante entender como dentro de los años sesenta y setenta se creó en Holanda un incipiente movimiento de la (ultra)izquierda, el Angola Comité, que inicialmente se posicionó claramente a la izquierda del Partido Comunista, pero que llegó a tener una influencia moral dentro de un segmento amplio de ciudadanos que simpatizaron y financiaron ampliamente la lucha anticolonial de las colonias portuguesas y el apartheid surafricano. El Angola Comité terminó de funcionar unos años después de que se iniciase el gobierno de Nelson Mandela en 1990.

Dos fundadores del CIDAc tuvieron cargos relevantes de gobierno. Luis Moita fue secretario de Estado (viceministro) en uno de los seis gobiernos provisorios entre 1974 y 1976; y Jorge Sampaio llegó a ser presidente de Portugal entre 1996 y 2006. Pero la institución y la mayoría de los activistas optaron por el camino del apoyo civil a las excolonias portuguesas. El CIDAC de hoy, septiembre de 2020, es una ONG de documentación y actividades de apoyo a

2018. Ahora el Reino de los Países Bajos cuenta con tres "países" y tres "municipios especiales" ultramarinos adicionales. 
las excolonias portugueses, especialmente a Timor del Este y Guinea-Bissau, los dos países que han sufrido más guerras civiles e invasiones exteriores.

En comparación con los movimientos de liberación y la guerrilla en América Latina y el Caribe, la situación de África era mucho más complicada y las guerras civiles fueron más largas y se involucraron más potencias y terceros países (Kruijt, Rey Tristán y Martín Álvarez, 2020). Las anteriores colonias portuguesas pasaron por problemas durante décadas después de la independencia (Chabal et al., 2002). Guinea-Bissau entró en un largo periodo de inestabilidad, golpes y contragolpes militares (Nóbrega, 2003). En Mozambique y Angola se iniciaron guerras civiles sanguinarias (Finnegan, 1992; Messiant, 2008; Oliveira, 2015).

El proceso acelerado de descolonización, ¿era inmadurez? En una entrevista con André Franco de Sousa, dirigente de la Liga Nacional Africana y uno de los miembros fundadores del MPLA, da el siguiente intercambio de opiniones (Drumond y Barber, 1999):

P: ¿Con eso quiere decir que los Angolanos no estuvieron preparados para la independencia?

$\mathrm{R}$ : La misma pregunta me fue hecha por sus colegas de la TV española después del 25 de abril. ¿Sabe qué fue mi respuesta a ellos? Era así: "Portugal estuvo más o menos 40 años bajo la dictadura del profesor Oliveira Salazar. Angola estuvo 40 años debajo del profesor Oliveira Salazar. Cuando me pregunta si ahora estamos preparados, ¿Es cuestión de raza?” Esa fue mi respuesta y a usted respondo de la misma manera (p. 67).

\section{LISTA DE REFERENCIAS}

Almeida, J. M. (2008). A oposição católica ao Estado Novo, 1958-1974. Lisboa: Edições Nelson de Matos.

BAC (1975). Boletim Anti-Colonial (Número 1-9 do BAC, 1972-73). Porto: Edições Afrontamento.

Bernts, T. y Berghuis, J. (2016). God in Nederland 1966-2015 [Dios en Holanda 19662015]. Utrecht: Ten Hove.

Beurden, J. van y Huinder, C. (1996). De vinger op de zere plek: Solidariteit met Zuidelijk Afrika 1961-1996 [El dedo en el punto lastimado: Solidaridad con África Austral 19611996], prefacio de Nelson Mandela. Amsterdam: Babylon/De Geus. 
Bosgra, S. et al. (2005). Brothers from the West. Solidariry in the Netherlands with Mozambique 1962-2005/Irmãos do Ocidente. Solidariedade na Holanda com Moçambique 1962-2005. Amsterdam: Netherlands Institute for Southern Africa (NIZA)/Arquivo Histórico de Moçambique-Universidade Eduardo Mondlane.

Carmo, I. do (2017). Luta Armada. As Brigadas Revolucionária, a ARA e a LUAR contados pelos próprios protagonistas. $E$ os dias de fúria da Europa rebelde da segunda metade do século xx. Alfragide: Dom Quixote.

Chabal, P. et al. (2002). A history of postcolonial Lusophone Africa. Londres: Hurst \& Co.

Chabot, J. (2013). Nooit meer bacalhau. Terugblik van een tropenarts op een heftig jaar in zich bevrijdend Angola [Nunca más bacalhaõ. Un médico tropical reflexiona sobre un año violento en Angola que se está liberando]. Heelsum: Brave New Books.

Chilcote, R. H. (2012). The Portuguese Revolution. State and class in the transition to democracy. Landham: Rowman \& Littlefield.

Coelho, J. P. Borges (2015). As tropas africanas no exército colonial português, 19611974: Angola, Guiné Bissau e Moçambique. En A. J. Venter, Portugal e as guerrilhas de África. As guerras portuguesas em Ángola, Moçambique e Guiné 1961-1974 (pp. 473487). Lisboa: Clube de Autor S. A.

Correia, P. de Pezarat (2017)....da descolonização. Do protonacionalismo ao pós-colonialismo. Porto: Book Cover Editora.

Correia, P. de Pezarat (2018). Do lado certo da história. Entrevista de María Manuela Cruzeiro. Lisbon and Coimbra: Âncora Editora/Centro de Documentação 25 de Abril/Cover Editora.

Cruz Rodrigues, F. da (2013). A desmobilização dos combatentes africanos das Forças Armadas Portuguesas da Guerra Colonial (1961-1974). Ler História. O Corpo do Estado-Maior do Exército Português. DoI: https://doi.org/10.4000/lerhistoria.484

Drumond, J. y Barber, H. (coords.). (1999). Angola: Depoimentos para a história recente. Vol. 1. S/l: Edição de Autor.

Ferraz, R. (2019). Grande guerra e guerra colonial: Quanto custaram aos cofres portugueses? Lisboa: Gabinete de Estratégia e Estudos do Ministério da Economia, GEe Paper 122. Recuperado de https://www.gee.gov.pt//RePEc/WorkingPapers/GEE_PAPERS_122.pdf

Finnegan, W. (1992). A complicated war. The Harrowing of Mozambique. Berkeley: University of California Press.

George, E. (2005). The Cuban intervention in Angola, 1965-1991. From Che Guevara to Cuito Cuanavale. Londres: Frank Cass.

Gomes, C. de Matos y Alfonso, A. (coords.). (2009a). Os anos da guerra colonial 19611994. (16 vols.). Lisboa: QuidNovi 
Gomes, C. de Matos y Alfonso, A. (coords.). (2009b). Os anos da guerra colonial 19611994. Vol. I. Os anos que geram um novo mundo. Lisboa: QuidNovi.

Guerra, J. P. (2009). Descolonização portuguesa: O regresso das caravelas (prefacio de Ernesto Melo Antunes). Alfragide: Oficina do Livro.

Hendrix, H. (2006). Namibia and the Netherlands. 350 years of relations (prefacio de Marco Hausiku, Minister of Foreign Affairs of the Republic of Namibia). Windhoek: Embassy of the Kingdom of the Netherlands.

Kapuscinski, R. (2001). Another day of life. Harmondsworth: Penguin Classics.

Kruijt, D. (2017). Cuba and revolutionary Latin America, An oral history. Londres: ZED Books.

Kruijt, D., Rey Tristán, E. y Martín Álvarez, A. (coords.). (2020). Latin American guerrilla movements: Origins, evolution, outcomes. Nueva York: Routledge.

Kuitenbrouwer, M. (1994). De ontdekking van de Derde Wereld: beeldvorming en beleid in Nederland 1950-1990 [El descubrimiento del Tercer Mundo: Imagen y políticas en los Países Bajos 1950-1994]. La Haya: SDU Uitgevers.

KzA (1981). Twintig jaar Angola Comité [Veinte años del Angola Comité]. Amsterdam: Komité Zuidelijk Afrika (Angola Comité).

Liebenberg, I., Risquet, J. y Shubin, V. (coords.). (2005). A far-away war: Angola, 19751989. Stellenbosch: SUN Media.

Marques, A. (2013). Segredos da descolonização de Angola. Alfragide: Publicações Dom Quixote.

Matias, A. (2004). Entre o BAC e o CIDAC. En A cor das solidariedades. 30 anos do CIDAC. (pp. 21-25). Santa Maria da Feira: Edições Afrontamento.

Maxwell, K. (2010). The making of Portuguese democracy. Cambridge: Cambridge University Press.

Messiant, C. (2008). L’Angola postcolonial. I: Guerre et paix sans démocratisation. París: Karthala.

Muskens, R. (2014). Aan de goede kant. Biografie van de Nederlandse anti-apartheids beweging, 1960-1990. [Al lado bueno. Biografía del movimiento anti-apartheid de los Países Bajos, 1960-1990]. Soesterberg: Aksent.

Nóbrega, Á. (2003). A luta pelo poder na Guiné-Bissau. Lisboa: Universidade Técnica de Lisboa-Instituto Superior de Ciências Sociais e Políticas.

Oliveira, R. Suares de (2015). Magnificent and beggar land: Angola since the civil war. Londres: Hurst \& Co.

Oostindie, G. (2015). 'De gewelddadige dekolonisatie van Nederlands-Indië [La descolonización violenta de India Holandesa]'. Historisch Nieuwsblad, 6. Recuperado 
de https://www.historischnieuwsblad.nl/nl/artikel/43318/de-gewelddadige-dekolonisatie-van-nederlands-indie.html

Pinto, A. Costa y Rezola, M. I. (2007). Political catholicism, Crisis of democracy and Salazar's new State in Portugal. Totalitarian Movements and Political Religions, 8(2), 353-368. DoI: https://doi.org/10.1080/14690760701321320

Pires, R. Pena (2003). Migrações e integração. Teoria e aplicações a sociedade portuguesa. (Tesis de Doctorado inédita). Instituto Universitário Lisboa (ISCTE)-Departamento de Sociologia, Lisboa.

Rodrigues, R. (1995). Os últimos guerreiros do Imperio. Almadora: Editora Erasmos.

Santos, J. (2014). Conversa com Luísa Teotónio Pereira, por Júlio Santos. Sinergias-diálogos educativos para a transformação social, 1, 116-127. Recuperado de http:// www.sinergiased.org/index.php/revista/item/17-conversa-com-luisa-teotonio-pe reira-por-julio-santos

Teotónio Pereira, L. (2004). Encruzilhada de solidariedades. En A cor das solidariedades. 30 anos do CIDAC (pp. 27-50). Santa Maria da Feira: Edições Afrontamento.

Teotónio Pereira, N. (2004). Da guerra colonial à Capelo do Rato. En A cor das solidariedades. 30 anos do CIDAC (pp. 17-19). Santa Maria da Feira: Edições Afrontamento, pp. 17-19.

Varela, R. (2018). A people's history of the Portuguese Revolution. Londres: Pluto Press.

Venter, A. J. (2015). Portugal e as guerrilhas de África. As guerras portuguesas em Ángola, Moçambique e Guiné 1961-1974. Lisboa: Clube de Autor S.A.

Waals, W. S. van der (2011). Portugal's war in Angola, 1961-1974. Pretoria: Protea Book House.

Wessels, A. (2017). Half a century of South African "Border War" literature: A historiographical exploration. Southern Journal for Contemporary History, 42(2), 24-47. DOI: https://doi.org/10.18820/24150509/JCH42.v2.2 